\title{
STUDI TENTANG BANDENG PRESTO CRYSPY PADA INDUSTRI RUMAH TANGGA (IRT) "BU JENI" DI KELURAHAN TUNJUNG SEKAR KOTA MALANG
}

\author{
Sudiyono $^{1 *}$, Sukamto ${ }^{2}$ \\ 1,2Jurusan Teknologi Hasil Pertanian, Fakultas Pertanian, Universitas Widyagama Malang \\ *Email Korespondensi : sudiyono@widyagama.ac.id
}

\begin{abstract}
ABSTRAK
Bandeng presto krispi merupakan salah satu produk pangan tradisonal masyarakat Jawa yang dimodifikasi dengan menambah krispi untuk menambah daya tariknya. Salah satu industri rumah tangga (IRT) yang memproduksi bandeng presto adalah "Bu Jeni”yang berlokasi di kelurahan Tunjung Sekar, kota Malang. Tujuan kegiatan adalah untuk mempelajari teknologi proses produksi dan manajemen sebagai upaya memperbaiki kualitas produk bandeng presto agar mampu meningkatkan daya saing dan segementasi pasar. Metode pelaksanaan kegiatan yang dilakukan pada bulan Juni sampai Desember 2019 dengan cara survey, wawancara langsung dan memberi solusi alternatif. Hasil kegiatan menunjukan bahwa proses produksi bandeng presto masih terbatas kapasitasnya yang menggunakan alat presto berkapasitas $5 \mathrm{~kg}$. Bidang manajemen dan pemasaran produk mengalami peningkatan 10-20 persen pada tahun 2019 dibandingkan tahun 2018. Konsumen yang menjadi pelangga bandeng presto "Bu Jeni" masih bersifat lokal dan mulai berkembang keluar daerah sebagai oleh-oleh. Kesimpulan dari hasil kegiatan adalah bahwa produk bandeng presto sangat potensi untuk dikembangkan menjadi produk andalan usaha kecil menengah, di pasaran lokal maupun regional. Sedangkan sentuhan teknologi, manajemen produksi dan pemasaran perlu dikembangkan secara berkelanjutan.
\end{abstract}

Kata kunci : Bandeng presto, Industri rumah tangga, Manajemen, Produksi

\begin{abstract}
Crispy milkfish presto is one of the traditional food products of the Javanese community which is modified more crispy to increase its appeal. One of the home industries (IRT) that produces milkfish presto is Mrs Jeni, located in Tunjung Sekar, Malang. The activity aims to study the technology of production and management processes as an effort to improve the quality of presto milkfish products in order to be able to increase market competitiveness and segmentation. The activities conducted from June to December 2019 using surveys, direct interviews and providing alternative solutions. The results of the activity show that the production process of presto Milkfish is still limited in its capacity using a $5 \mathrm{~kg}$ Presto tool. The field of product management and marketing has increased by 10-20 percent in 2019 compared to 2018. Consumers who are customers of Bu Jeni's prestige milkfish are still local and have begun to develop outside the region as souvenirs. The activity concludes that the presto milkfish product has the potential to be developed into a reliable product of small and medium businesses, in the local and regional markets. At the same time, the touch of technology, production management and marketing needs to be developed sustainably.
\end{abstract}

Keyword : milkfish presto, Home industry, Management, Production

\section{PENDAHULUAN}

Bandeng presto adalah makanan khas Indonesia yang berasal dari Kota Semarang, Jawa Tengah. Makanan ini dibuat dari ikan bandeng (Chanos chanos) yang dibumbui dengan bawang putih, kunyit dan garam. Ikan bandeng ini kemudian dimasak pada alas daun pisang dengan cara presto. Presto adalah cara memasak dengan uap air yang bertekanan tinggi. Makanan yang dimasak dengan cara ini diletakkan dalam panci yang dapat dikunci dengan rapat. Air yang berada di dalam panci ini kemudian dipanaskan hingga mendidih. Uap air yang timbul akan memasak makanan yang berada di dalam panci ini. Karena ikan bandeng 
terkenal memiliki banyak duri, maka dengan dimasak menjadi bandeng presto menjadi lebih digemari karena duri-durinya menjadi sangat lunak (http://wikipedia.org/wiki/bandeng presto).

Bandeng presto krispi yang diproduksi oleh IRT "Bu Jeni" berpotensi untuk dikembangkan sebagai produk untuk lauk makan dan dapat dijadikan oleh-oleh, karena produknya unik dan telah diminati oleh konsumen secara luas. Usaha bandeng presto pada IRT “Bu Jeni”tersebut berdiri sejak tahun 1985. Kriteria bandeng presto yang baik diukur melalui dua aspek yaitu aspek subyektif dan obyektif, aspek subyektif yang terdiri dari warna bandeng presto kuning kecoklatan, tekstur yang lunak dan krispi serta rasa yang gurih, sedangkan aspek obyektif mirip dengan syarat mutu bandeng presto dimana syarat tersebut sesuai dengan standar yang telah ditetapkan departemen perindutrian yaitu SNI-4106-12009. Permasalahan yang dihadapi oleh IRT bandeng presto "Bu Jeni" adalah (1). Teknologi produksi, manajemen dan pemasaran sebagian besar masih menggunakan cara-cara konvensional dan (3). Perlindungan hukum, labelling, merek dan jaminan halal masih sangat lemah. Permasalahan tersebut dapat mengakibatkan posisi tawar IRT menjadi semakin turun.

Tujuan pelaksanaan kegiatan pengabdian masyarakat ini adalah (1). mempelajari teknik produksi dan pemasaran bandeng presto di IRT "Bu Jeni", (2) melakukan identifikasi terhadap permasalahan teknologi produksi dan standarisasi bahan baku produksi bandeng presto, manajemen, penanganan produk akhir dan pemasaran bandeng presto termasuk perlindungan hukum terhadap produk di IRT "Bu Jeni". (3). Memberikan solusi alternatif terhadap permasalahan yang telah teridentifikasi.

\section{METODE}

Metode pelaksanaan kegiatan dalam pengabdian msyarakat ini melilputi beberapa bentuk kegiatan diantaranya adalah :

\section{Penyamaan presepsi}

Penyamaan presepsi ditempuh melalui diskusi dan saling pengertian antara tim pelaksana dengan mitra IRT bandeng presto "Bu Jeni". Diskusi dilakukan secara intensif dilakukan untuk mencari solusi dari permasalahan yang telah teridentifikasi. Hal ini dimaksudkan untuk menghindari konflik apabila solusi alternatif yang telah disepakati bersama diimplementasikan selama program PKM dijalankan.

\section{Implementasi solusi bidang teknologi produksi}

Implementasi solusi bidang teknologi produksi difokuskan pada peningkatan kualitas bandeng presto krispi, yang dilakukan dengan cara pendampingan dalam hal pemilihan bahan baku (khususnya ikan bandeng), pengoperasian alat presto serta cara penggorengan.

\section{Pelatihan dan pendampingan bidang manajerial}

Selama proses usahanya berlangsung IRT "Bu Jeni" tidak pernah melakukan pencatatan transaksinya ke dalam jurnal umum. Catatan dilakukan secara tradisional dan sangat sederhana dengan mendeskripsikan setiap transaksi yang terjadi dan belum diteruskan pada pembuatan neraca lajur atau kertas kerja atau worksheet. Oleh karena itu dilakukan pelatihan dan pendampingan tentang :

a. Cara merancang dan menyajikan pembuatan akun dan penomoran berdasarkan transaksi-transaksi yang terjadi.

b. Pencatatan ke dalam jurnal umum

\section{Implementasi solusi pada bidang kelembagaan}

Melatih dan mendampingi mitra dalam proses pendaftaran ijin Industri Rumah Tangga (PIRT). 
Dalam melaksanakan seluruh program yang ditetapkan dibutuhkan partisipasi mitra. Bentuk partisipasi mitra tersebut antara lain ádalah:

a. Bersedia berdiskusi dan berpartisipasi akatif bersama tim pelaksana dalam pelaksanaan program pelatihan dan pendampingan.

b. Ikut memberikan saran dan masukan.

c. Bersedia bekerjasama secara berkelanjutan.

\section{HASIL DAN PEMBAHASAN}

\section{Penanganan Dan Standarisasi Bahan Baku}

Selama pelaksanaan program PKM, beberapa hal yang telah disepakati antara mitra dan pelaksana kegiatan telah berjalan sesuai dengan yang direncanakan. Dalam aspek proses produksi telah dilakukan pendampingan dalam hal pemilihan bahan baku (khususnya ikan bandeng). Kepada mitra diajarkan untuk mengenali cirri-ciri ikan bandeng yang masih segar, diantaranya adalah bau yang tercium khas bau ikan (amis dan tidak berbau busuk), sisik ikan masing lengkap dan kelihatan mengkilap, mata ikan masih jernih dan masih terdapat lendir. Dengan memahami cirri-ciri ikan bandeng yang masih segar, diharapkan produk bandeng presto krispi yang dihasilkan akan memiliki kualitas yang lebih baik (Hadiwiyoto, 1993; Husaini, 1989; Murniati \& Sunarman, 2000; Syarief, et al., 1989).

Untuk menunjang keberlanjutan kegiatan IRT bandeng presto "Bu Jeni"menggunakan bahan baku utama berupa ikan bandeng segar. Kebutuhan bahan baku utama pada IRT " $\mathrm{Bu}$ Jeni”setiap hari adalah ikan bandeng segar sebanyak $10 \mathrm{~kg}$. Sedangkan bahan-bahan penunjangnya adalah bawang putih, kunyit, garam, telur dan tepung terigu. Juga digunakan bahan rempah-rempah seperti daun salam dan daun pandan wangi. Jumlah tersebut bisa meningkat dengan tajam pada bulan-bulan tertentu seperti menjelang idul Fitri, tahun baru dan bulan-bulan dimana orang banyak punya hajad, serta pada waktu banyak orang pulang kampung karena liburan. Keterbatasan ketersediaan bandeng segar dipasar menjadi kendala tersendiri bagi IRT "Bu Jeni”karena bersifat musiman sehingga berpengaruh pada harga. Untuk menghasilkan bandeng presto yang berkualitas baik maka spesifikasi bahan baku yang diperlukan harus memenuhi standar (Gambar 1).

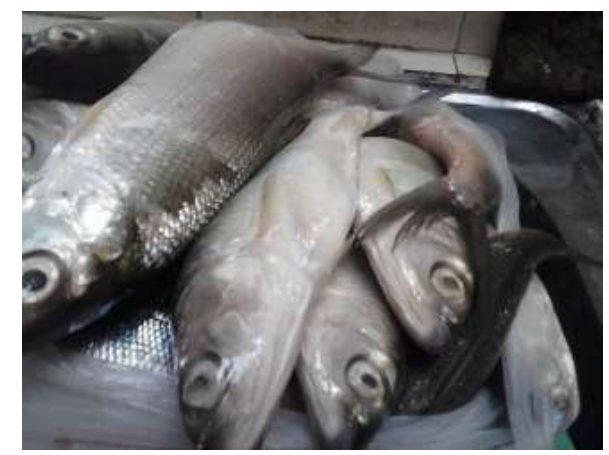

Gambar 1. Bahan baku utama bandeng presto

Ikan bandeng segar yang digunakan dengan ukuran sedang ( $1 \mathrm{~kg}$ berisi antara 5-6 ekor), dihilangkan sisik dan isi perutnya kemudian dicuci sampai bersih. Selanjutnya ikan bandeng yang sudah bersih dimasak dengan cara dipresto lebih kurang 1-1.5 jam. Sebelumnya ditambahkan bumbu-bumbu seperti bawang putih, kunyit dan daun salam. Bahan tersebut selanjutnya didinginkan dengan cara dimasukkan kedalam kulkas menunggu untuk digoreng. Selanjutnya digoreng dengan menambahkan adonan krispi yang membalut 
seluruh ikan bandeng prestonya. Kontrol kualitas pada bahan baku dilakukan pada pemilihan ikan bandeng yang masih segar dengan ciri-ciri sisik masih menempel dengan kuat, mata masih jernih dan tidak berbau busuk (Balai Pengembangan dan Pengujian Mutu Hasil Perikanan, 2004; Direktorat Jenderal Perikanan, 1991).

\section{Teknologi Proses Produksi}

Alat presto yang dimiliki oleh mitra ada yang ukurannya kecil (kapasitas $5 \mathrm{~kg}$ ) dan ada yang berkapasitas $25 \mathrm{~kg}$. Dalam penggunaan alat presto oleh mitra terdapat kendala yaitu takut untuk menggunakan alat presto yang berkapasitas $25 \mathrm{~kg}$ (takut meledak) dan hasil bandeng prestonya berbau logam (karena bahannya dari besi cor dan bukan steenleis steel food grade). Sehingga diperlukan pemahaman cara pengoperasian yang benar dan cara perawatan yang baik untuk menghindari terjadi meledak (karena tersumbatnya aliran uap panas yang keluar dari alat). Kedepannya diupayakan untuk memberi lapisan steenleis steel food grade pada alat presto yang berkapatas $25 \mathrm{~kg}$ agar tidak berbau logam pada produk bandeng presto yang dihasilkan.

Proses produksi bandeng presto di Usaha Kecil Menengah (IRT) "Bu Jeni"sangat dipengaruhi oleh permintaan pasar. Rata-rata produksi $15 \mathrm{~kg}$ bandeng presto per hari. Jika dilihat dari peralatan yang tersedia kapasitas produksinya masih dapat memenuhi permintaan pasar. Rata-rata biaya produksi adalah Rp. 8.000,- per ekor produk bandeng presto krispi. Hasil pelaksanaan kegiatan menunjukkan bahwa proses produksi bandeng presto di IRT " $\mathrm{Bu}$ Jeni"memiliki 2 tahapan yaitu tahapan pembuatan bandeng presto dan tahapan proses penggorengan bandeng presto (Gambar 2). Sedangkan diskusi dan pelatihan yang diberikan kepada mitra dapat dilihat pada Gambar 3 sampai Gambar 11.

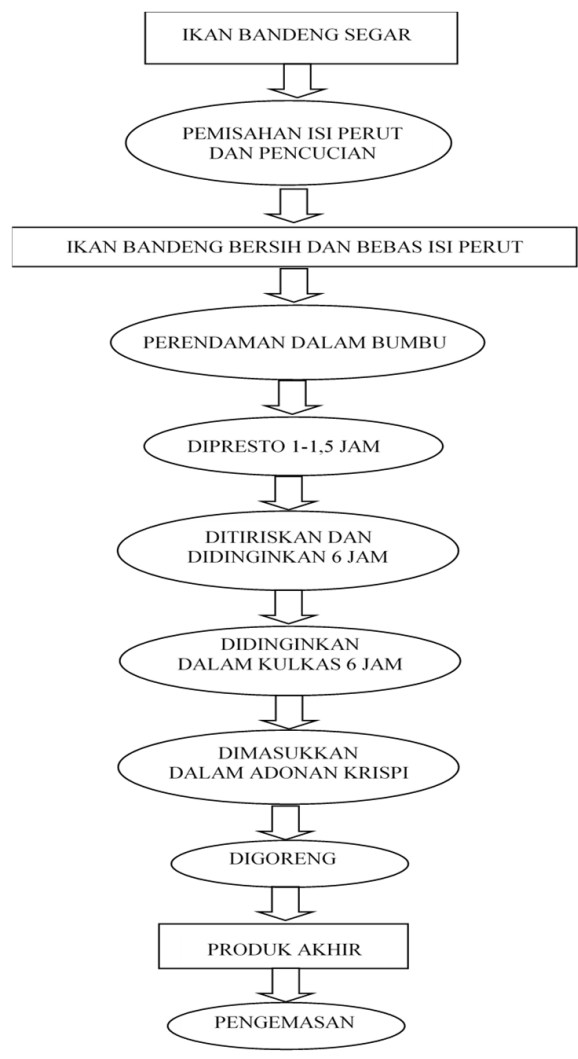

Gambar 2. Diagram alir proses produksi bandeng presto di IRT "Bu Jeni" 


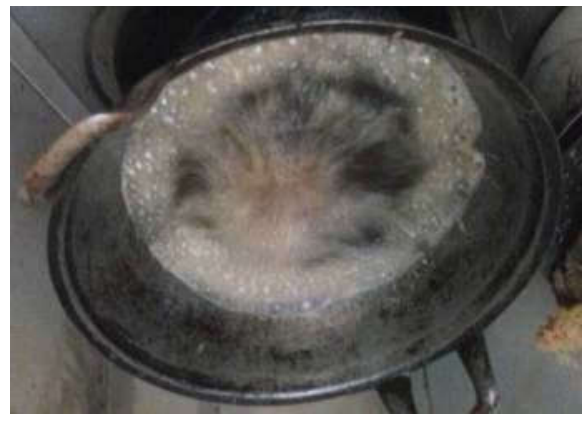

Gambar 3. Proses penggorengan bandeng presto

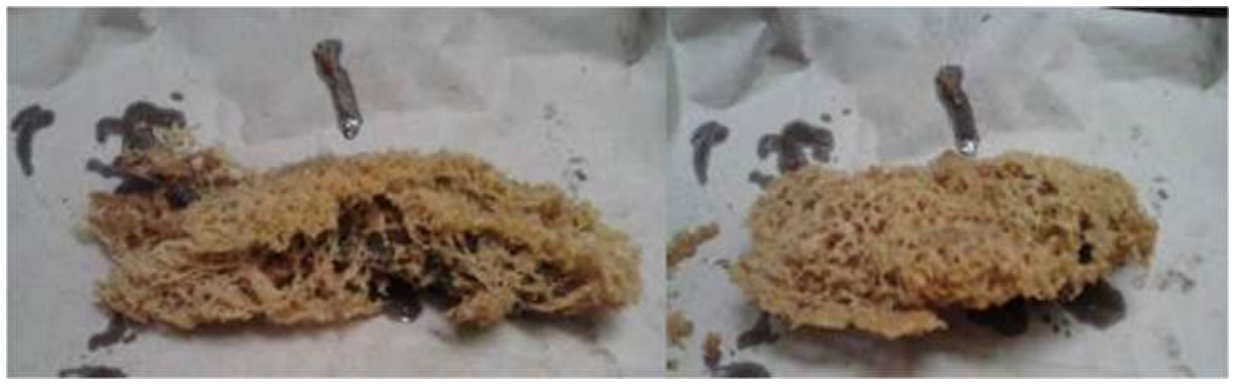

Gambar 4. Produk akhir bandeng presto krispi

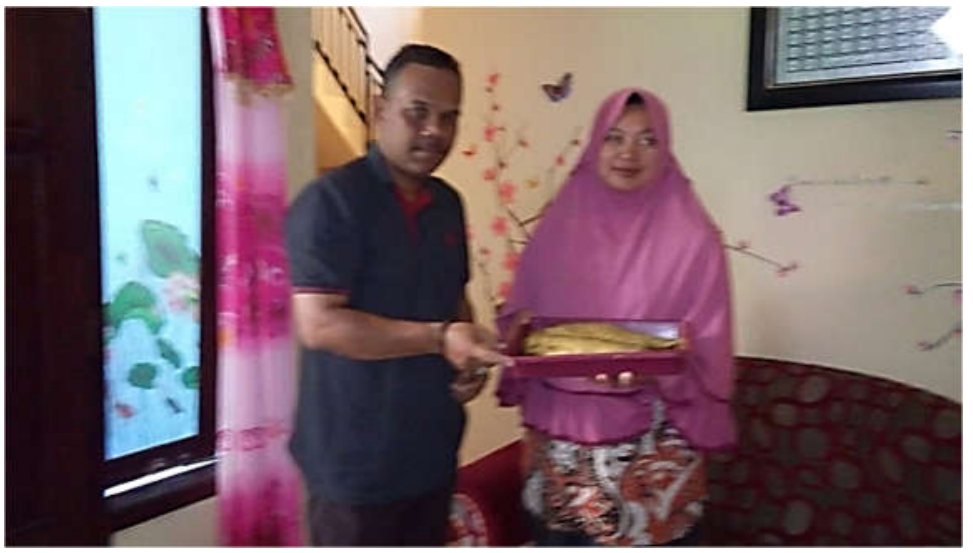

Gambar 5. Ikan Bandeng Presto Krispi Produksi IRT "Bu Jeni”

Pengurusan perijinan (PIRT) sudah dilakukan sampai dengan mitra mengikuti pelatihan sehari yang diadakan di Dinas Kesehatan Kota Malang sebagai salah syarat untuk memperoleh nomor PIRT. Saat ini pihak mitra ( IRT "Bu Jeni"), sedang menunggu survey lokasi oleh pihak Dimas Kesehatan Kota Malang ke lokasi mitra, untuk memastikan bahwa kegiatan proses produksi bandeng presto yang dilakukan sesuai dengan proses yang diperoleh selama mengikuti pelatihan.

Untuk meningkatkan kepercayaan konsumen terhadap kualitas bandeng presto yang dihasilkan oleh IRT "Bu Jeni", tim pelaksana juga sudah membuat disain kemasan yang digunakan untuk mengemas bandeng presto krispi yang akan dibawa ke luar kota sebagai oleh-oleh. Desain kemasan yang sudah dibuat sudah mencantumkan nama produk, merk dagang, informasi bahan baku, informasi cara penyimpanan, informasi tanggal kadaluwarsa dan nomor PIRT. Dengan adanya kemasan atau label yang representatif, dapat meningkatkan kepercayaan konsumen dan diharapkan dapat meningkatkan omzet penjualan.

Dalam bidang manajemen, tim pelaksana juga telah melakukan pendampingan mengenai pembukuan mengenai pencatatan pemasukan dan pengeluaran. Hal ini sangat 
penting supaya mitra dapat mengatur omzet pendapatan yang diperoleh dari penjualan bandeng presto yang dihasilkan tersebut.

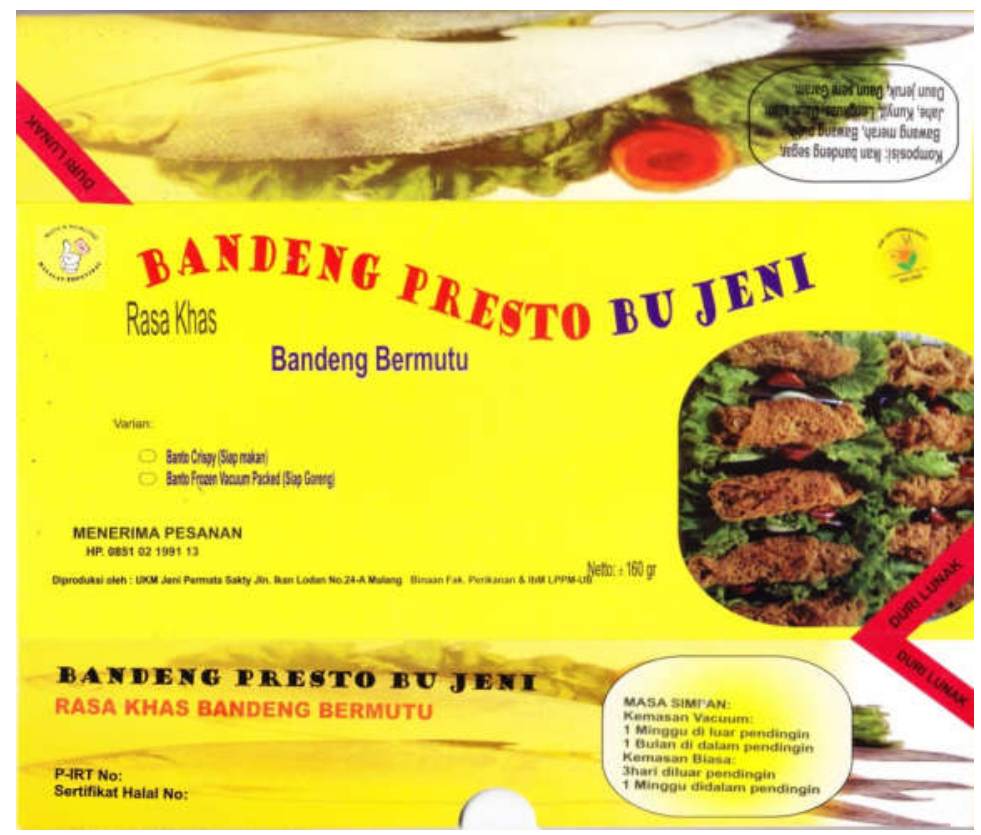

Gambar 10. Disain Kemasan Bandeng Presto Produksi IRT "Bu Jeni”"

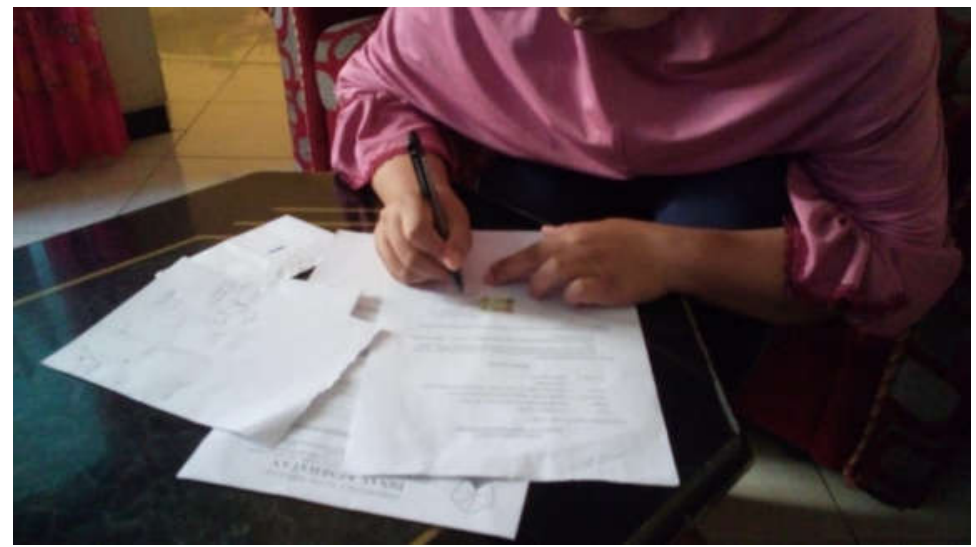

Gambar 11. Pelatihan Pembukuan Usaha

\section{DAMPAK DAN MANFAAT}

Dampak dan manfaat setelah dilakukan kegiatan ini adalah:

1. Dalam aspek proses produksi telah dilakukan pendampingan dalam hal pemilihan bahan baku menjadi lebih baik.

2. Disain kemasan bandeng presto krispi telah dilakukan disain ulang yang lebih menarik dan mencantumkan nama produk, merk dagang, informasi bahan baku, informasi cara penyimpanan, informasi tanggal kadaluwarsa dan nomor PIRT. Dengan adanya kemasan atau label yang representatif, dapat meningkatkan kepercayaan konsumen dan diharapkan dapat meningkatkan omzet penjualan. 


\section{KESIMPULAN}

Pelaksanaan program PKM di IRT bandeng presto krispi "Bu Jeni” telah berjalan dengan baik. Hal ini karena telah disepakati oleh kedua belah pihak tentang apa-apa saja yang akan dilakukan. Pengurusan surat perijinan (PIRT) dari Dinas Kesehatan Kota Malang sudah dilakukan, sehingga IRT "Bu Jeni" memiliki pemahaman yang baik mengenai cara berproduksi makanan yang baik. Harapannya dengan memperoleh surat ijin (PIRT) akan dapat meningkatkan kepercayaan konsumen sehingga dapat meningkatkan omzet pemasaran. Disamping dapat meningkatkan image produk bandeng presto krispi produksi IRT "Bu Jeni" dimata konsumen, pembuatan disain kemasan juga bisa berfungsi untuk meningkatkan penampilan dan kebersihan produk bandeng presto "Bu Jeni".

\section{UCAPAN TERIMA KASIH}

Terima kasih kepada LPPM Universitas Widyagama Malang yang telah memberikan dana dalam pelaksanaan kegiatan melalui program Pengabdian Masyarakat (Propenmas) anggaran tahun 2019.

\section{REFERENSI}

Balai Pengembangan dan Pengujian Mutu Hasil Perikanan, (2004) 'Ikan Bandeng dan Produk Derivasinya', Departemen Kelautan dan Perikanan, Jakarta.

Direktorat Jenderal Perikanan, (1991) 'Standar Nasional Indonesia (SNI) 01-2345-1991, Uji Organoleptik Ikan Pindang', Badan Standarisasi Nasional, Jakarta.

Hadiwiyoto, S. (1993) 'Teknologi Pengolahan Hasil Perikanan', Liberty, Yogyakarta.

http://wikipedia.org/wiki/bandeng presto Diakses Oktober 2019

Husaini, (1989) 'Nilai Gizi Ikan dan Manfaatnya Untuk Keshatan dalam Mukadar dkk., Perbandingan Komposisi Asam Lemak Ikan Air Tawar dan Ikan Air Laut di perairan Indonesia', Jurnal Pasca Panen Perikanan, 9(1), 23-28.

Murniati dan Sunarman. (2000) 'Pendinginan, Pembekuan dan Pengawetan Ikan', Kanisius, Yogyakrta.

Syarief, R., Santausa, S. dan Isyana. S. T. (1989) 'Teknologi Pengemasan Pangan', Institut Pertanian Bogor, Bogor. 